\title{
The Role of the Amateur in Modern Astronomy
}

H. Derek Howse ${ }^{1}$, Patrick Moore ${ }^{2}$

${ }^{1} 12$ Barnfield Road, Riverhead, Sevenoaks, Kent TN132AY, U.K.

${ }^{2}$ Farthings, West Street, Selsey, Chichester, W. Sussex, U.K.

\section{Abstract}

This contribution dealt with the need for international coordination between amateur astronomers and the failure of the IUAA (International Union of Amateur Astronomers) to meet this need. [The substance of this contribution was given in Sky \& Telescope, 73, 482 (1987 November).The text was not received. - Eds.] 